\title{
Effect of Egg Shell Powder (ESP) on the Strength Properties of Cement-Stabilization on Olokoro Lateritic Soil
}

\section{Maduabuchi MN* and Obikara FO}

Department of Civil Engineering, Michael Okpara University of Agriculture, Nigeria

${ }^{*}$ Corresponding author: Maduabuchi MN, Department of Civil Engineering, Michael Okpara University of Agriculture, Umudike, PMB 7267, Umuahia 440109, Abia State, Nigeria, Email: michael.aroma@yahoo.com

\section{Research Article}

Volume 1 Issue 1

Received Date: July 30, 2018

Published Date: August 28, 2018

DOI: $10.23880 /$ oajwx-16000103

\section{Abstract}

The effect of eggshell powder or ash on the strength properties of cement-stabilization on Olokoro lateritic soil was studied. The eggshell was mixed with the cement-stabilized soil in the proportions of $3 \%, 6 \%, 9 \%, 12 \%$ and $15 \%$ and the geotechnical behavior of the soil was carefully observed. The results of the study showed that the strength properties of the A-6 soil, according to its AASHTO classification, improved with the addition of eggshell ash. This also indicates that further addition of eggshell ash would thus; increase the strength properties of the stabilized soil further. However, eggshell ash has been established to be a good accelerator for cement-bound materials and this would be very vital for road construction work especially during the rainy seasons for minimizing the setting time of stabilized road pavements. The study also exposes the engineering value of this agricultural material which probably causes disposal problems, leading to environmental pollution.

Keywords: Olokoro; Lateritic Soil; Egg Shell Powder; Cement-Stabilization; Geotechnical Properties

Abbreviations: ESP: Egg Shell Powder; CBR: California Bearing Ratio; NGS: Nigeria General Specification; AASHTO: American Association of State Highway and Transportation Officials.

\section{Introduction}

In recent times, the demand for better flexible pavement materials accentuated by design guidelines that are based on the assumptions that aggregates are important ingredients of pavement structures, has increased due to increased constructional activities in the road sector and paucity of available construction materials in the developing countries [1]. Many research works have been carried out on roads to improve the strength of road bases. Such improvement is known as soil stabilization, which is concentrated on mixing two or more materials and compacting same to improve the strength of the treated soil [2]. Stabilization can increase the shear strength of soil and control the shrink-swell properties of a soil, thus improving the load bearing capacity of foundation soils [3]. Eggshell are agricultural wastes which when subjected to adequate preservation could be suitable for soil stabilization and this was confirmed by Alhassan and Mustapha [4,5]. About $7 \times 10^{7}$ metric tons of eggs are produced in the world yearly, 192640 metric tons are produced in Nigeria and $12.5 \%$ of 192640 metric tons are produced by the local 
hens [6]. Eggshell, preferably the chicken eggshell perceived as waste material could be annexed for use as a replacement for soil stabilizer like lime since they both share the same chemical composition [7]. Egg shells in the construction industry can replace $10-30 \%$ of cement in a mix and can also improve the properties of concrete such as durability and creep [8]. So many researches were made using egg shell ash to check its effect on stabilizing agents like lime cement, common salt, bamboo leaf ash etc. and these yielded positive results $[7,9,10]$. There is an alarming rate of road pavement decay or failure in the Southeastern Nigeria and this research work aims at educating the relevant authorities and engineers at large on how to save the cost of pavement construction and other civil engineering works. This will be accomplished by ensuring that sub grade soils are improved in strength capacity by mixing a percentage of egg shell as ash with the soil or concrete.

\section{Methodology}

The soil sample used for this work was collected (using the disturbed sample technique) from a soil deposit in Olokoro, Umuahia South Local Government Area of Abia State, Nigeria. The sample was collected at a depth below $1.25 \mathrm{~m}$ to neglect the top soil and then airdried. UNICEM Ordinary Portland Cement was used as a binder and egg shell ash as replacement. Distilled water was used for mixing and the collected egg shells from local hens were ground, air-dried and incinerated to ash at a temperature of about $500^{\circ} \mathrm{C}$ and sieved through $75 \mu \mathrm{m}$ sieve in accordance with BS 12:1991 [11]. The stabilized mixtures were prepared by first of all mixing thoroughly dry Olokoro lateritic soil with cement and eggshell ash until a uniform color was attained after which water was added. Constant cement contents of $6 \%$ and $8 \%$ with variations of eggshell ash of $0 \%, 3 \%, 6 \%$, $9 \%, 12 \%$ and $15 \%$, by weight of the dry soil in all proportions of cement and eggshell ash were adopted for the mixes. The amount of water added was determined by the moisture-density relationship in which the Proctor mould was used to place the soil-cement eggshell ash mixtures in 3 layers and 25 blows were given onto each layer. The California Bearing Ratio was modified to correspond with NGS, which stipulates that specimens should be cured for 6 days and immersed in water for 24 hours before testing while the unconfined compressive strength specimens were cured for 7 days before testing [12]. The resistance to loss in strength (durability) was evaluated in accordance with BS 1924, which specifies it as a ratio of the Unconfined Compressive Strength of specimens cured for 7 days and later immersed in water for another 7 days to the unconfined compressive strength of specimens cured for 14 days [13].

\section{Results and Discussions}

The results of the Olokoro lateritic soil are given in Table 1 below.

\begin{tabular}{|c|c|c|}
\hline S/No & Properties & Results \\
\hline 1 & Color & Brown \\
\hline 2 & \multicolumn{2}{|c|}{ Grain Size Distribution } \\
\hline $\mathrm{i}$ & $\begin{array}{c}\text { Percentage passing sieve } \\
\text { no } 200\end{array}$ & 45.3 \\
\hline ii & Uniformity Coefficient, $C_{u}$ & 5.6 \\
\hline iii & Coefficient of Curvature, $C_{c}$ & 0.11 \\
\hline 3 & \multicolumn{2}{|c|}{\begin{tabular}{|c|} 
Atterberg Limits \\
\end{tabular}} \\
\hline $\mathrm{i}$ & Liquid Limit \% & 39 \\
\hline ii & Plastic Limit \% & 26.5 \\
\hline iii & Plasticity Index & 12.5 \\
\hline iv & Consistency Index \% & 42.4 \\
\hline 4 & \multicolumn{2}{|c|}{ Specific Gravity } \\
\hline $\mathrm{i}$ & Specific Gravity & 2.72 \\
\hline 5 & \multicolumn{2}{|c|}{ Soil Classification } \\
\hline $\mathrm{i}$ & AASHTO Classification & A-6 \\
\hline ii & $\begin{array}{c}\text { Unified Classification } \\
\text { System }\end{array}$ & SC (Clayey Sand) \\
\hline 6 & \multicolumn{2}{|c|}{ Major Clay Mineral Present } \\
\hline $\mathrm{i}$ & Major Clay Mineral Present & $\begin{array}{c}\text { Illite (Inorganic Clay of } \\
\text { Medium Plasticity) }\end{array}$ \\
\hline 7 & \multicolumn{2}{|c|}{ Compaction Characteristics } \\
\hline $\mathrm{i}$ & Max. Dry Density $\left(\mathrm{g} / \mathrm{m}^{3}\right)$ & 1.72 \\
\hline ii & $\begin{array}{c}\text { pptimum Moisture Conten } 1 \\
(\%)\end{array}$ & 14.2 \\
\hline iii & $\begin{array}{c}\text { California Bearing Ratio } \\
(\%)\end{array}$ & 9 \\
\hline
\end{tabular}

Table 1: Properties of Olokoro Lateritic Soil.

According to AASHTO classification, the soil was classified to be A- 6 and thus, it is said to be fairly good for road construction works. This is because it has a group index of 2 and its Atterberg limits (liquid limit of 39\%, plasticity index of $12.5 \%$ and plastic limit of $26.5 \%$ ) makes it satisfactory. Hence, clay mineral present in the lateritic soil (illite) is inorganic clay of medium plasticity and the activity is moderately satisfactory thus the soil would be somewhat stable in volume at moisture content variations. The high cement content requirement by the soil is attributed to the high percentage of finer particles (45.3\% passing Sieve No 200) in the soil. The coarse particles are almost inert in the reaction of the soil with 


\section{Open Access Journal of Waste Management \& Xenobiotics}

cement; rather the finer particles play the major role as the pozzolanic component in the reaction. Therefore higher finer particles results to higher cement content requirement.

\begin{tabular}{|c|c|c|c|c|c|c|}
\hline $\begin{array}{c}\text { Egg Shell Powder } \\
\text { (ESP) \% }\end{array}$ & $\begin{array}{c}\text { OMC } \\
\mathbf{( \% )}\end{array}$ & $\begin{array}{c}\text { MDD } \\
\mathbf{( g / \mathbf { m } ^ { 3 } )}\end{array}$ & $\begin{array}{c}\text { CBR } \\
\mathbf{( \% )}\end{array}$ & $\begin{array}{c}\text { LL } \\
\mathbf{( \% )}\end{array}$ & $\begin{array}{c}\text { PL } \\
\mathbf{( \% )}\end{array}$ & $\begin{array}{c}\text { PI } \\
\mathbf{( \% )}\end{array}$ \\
\hline 0 & 16.8 & 1.87 & 26.45 & 36 & 24.7 & 11.9 \\
\hline 3 & 16.9 & 1.85 & 27.19 & 35 & 23.7 & 11.3 \\
\hline 6 & 17.3 & 1.75 & 29.76 & 33 & 22.8 & 10.2 \\
\hline 9 & 17.9 & 1.72 & 53.54 & 31 & 22.6 & 8.4 \\
\hline 12 & 17.8 & 1.69 & 56.19 & 29 & 22.5 & 6.5 \\
\hline 15 & 17.9 & 1.67 & 58.24 & 29 & 22.5 & 6.5 \\
\hline
\end{tabular}

Table 2: Effects of Egg Shell Powder (ESP) on Olokoro Lateritic Soil Stabilized with 6\% Cement.

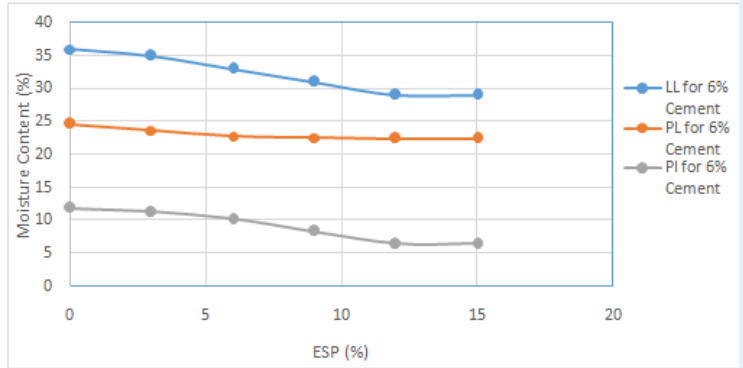

Figure 1: Graph of Atterberg Limits of Olokoro Soil Stabilized with 6\% Cement and Varying Percentages of ESP.

\begin{tabular}{|c|c|c|c|c|c|c|}
\hline $\begin{array}{c}\text { Egg Shell Powder } \\
\text { (ESP) \% }\end{array}$ & $\begin{array}{c}\text { OMC } \\
\text { (\%) }\end{array}$ & $\begin{array}{c}\text { MDD } \\
\left(\mathbf{g} / \mathbf{m}^{\mathbf{3}} \mathbf{)}\right.\end{array}$ & $\begin{array}{c}\text { CBR } \\
\mathbf{( \% )}\end{array}$ & $\begin{array}{c}\text { LL } \\
\mathbf{( \% )}\end{array}$ & $\begin{array}{c}\text { PL } \\
\mathbf{( \% )}\end{array}$ & $\begin{array}{c}\text { PI } \\
(\mathbf{\%})\end{array}$ \\
\hline 0 & 15.1 & 1.81 & 82 & 34 & 23.2 & 10.9 \\
\hline 3 & 14.7 & 1.76 & 85.4 & 32 & 22.9 & 9.1 \\
\hline 6 & 15.7 & 1.71 & 86 & 29 & 22.6 & 8.4 \\
\hline 9 & 16 & 1.7 & 88.5 & 29 & 20.7 & 8.3 \\
\hline 12 & 16.2 & 1.66 & 93.3 & 27 & 19 & 8 \\
\hline 15 & 16.6 & 1.63 & 93.4 & 26 & 18.4 & 7.6 \\
\hline
\end{tabular}

Table 3: Effects of Egg Shell Powder (ESP) on Olokoro Lateritic Soil Stabilized with 8\% Cement.

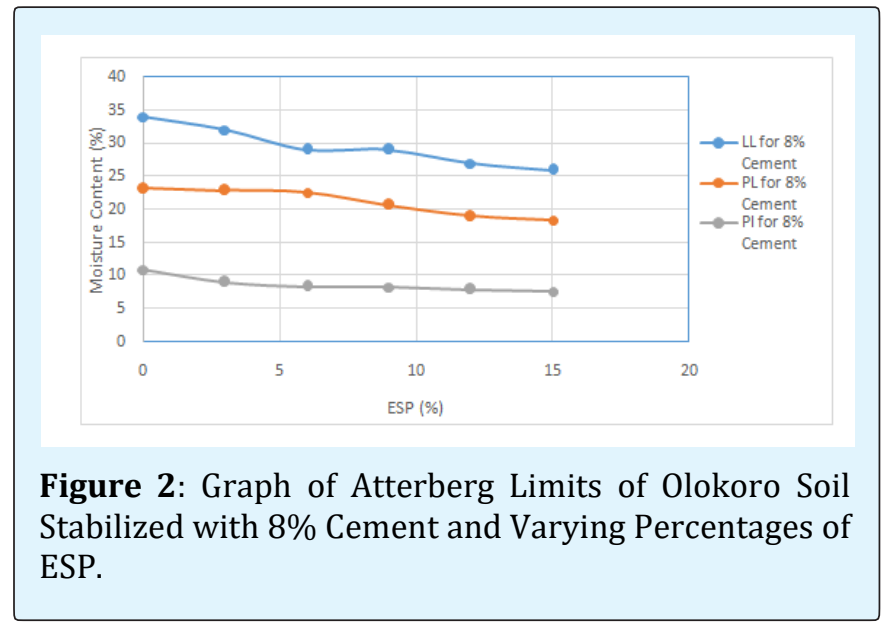

The increase of ESP brought about the reduction of the Atterberg limits of the soil, it is seen that the plastic limit, the liquid limit and plasticity index reduced gradually with increase in the percentage of ESP added. At 6\% cement at varying egg shell powder percentages it is seen that the plastic limit reduced from $24.7 \%$ to $22.5 \%$, and the liquid limit reduced from $36 \%$ to $29 \%$. It was also observed that the plasticity index also reduced from $11.9 \%$ to $6.5 \%$. Conversely, addition of $8 \%$ ESP reduced the liquid limit from $34 \%$ to $26 \%$, plastic limit from $23.2 \%$ to $18.4 \%$ and its plasticity index from $10.9 \%$ to $7.6 \%$. The subsequent decrease can be associated the agglomeration and flocculation of the clay particles as a result of ions' exchange at the surface of the clay particles. The reduction in plasticity index with chemical treatment could be attributed to the depressed double layer thickness due to caution exchange by potassium, calcium and ferric ions.

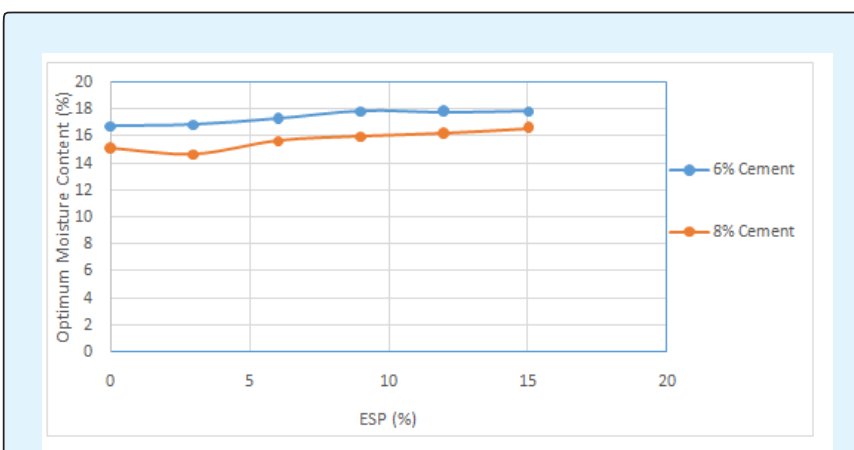

Figure 3: Variations of OMC with Increase in ESP at $6 \%$ and $8 \%$ Cement Stabilization. 
In Figure 3 above, it is observed that the Optimum Moisture Content increased with the addition of egg shell powder to the lateritic soil stabilized with cement. At 6\% cement, the OMC increased from $16.8 \%$ to $17.9 \%$, while an increase from $15.1 \%$ to $16.6 \%$ was observed at $8 \%$ cement stabilization. This increase is due to the absorption capacity of the egg shell powder as a result of its porous nature. Thus, increase in cement content stepup the hydration reaction of cement and consequently increases the demand for water in the system.

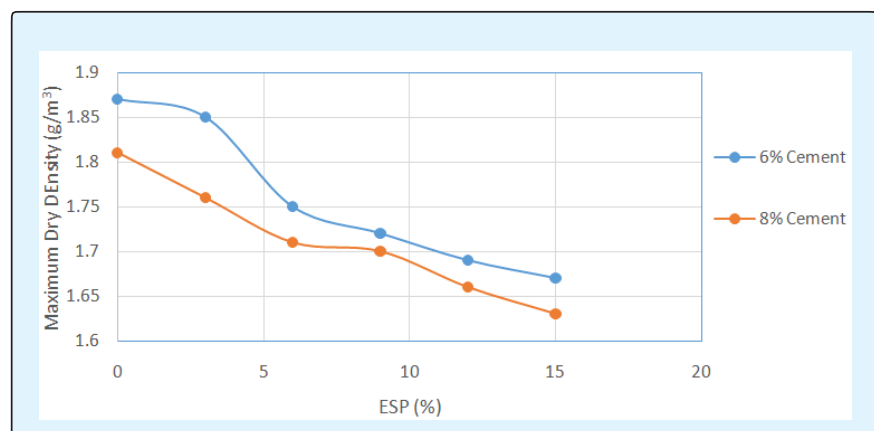

Figure 4: Variations of MDD with Increase in ESP at $6 \%$ and $8 \%$ Cement Stabilization.

From Figure 4 above, there is continuous decrease in Maximum Dry Density from $1.87 \mathrm{~g} / \mathrm{m}^{3}$ and $1.81 \mathrm{~g} / \mathrm{m}^{3}$ to $1.67 \mathrm{~g} / \mathrm{m}^{3}$ and $1.63 \mathrm{~g} / \mathrm{m}^{3}$ at $6 \%$ and $8 \%$ cement content respectively with the addition of eggshell ash of $0 \%$ to $15 \%$. This is as a result of the reaction between cement, eggshell ash and fine fractions of the soil as pozzolanic component in which they form clusters like coarse aggregates. These clusters occupied larger spaces thus increasing their volume and consequently decreasing the Maximum Dry Density.

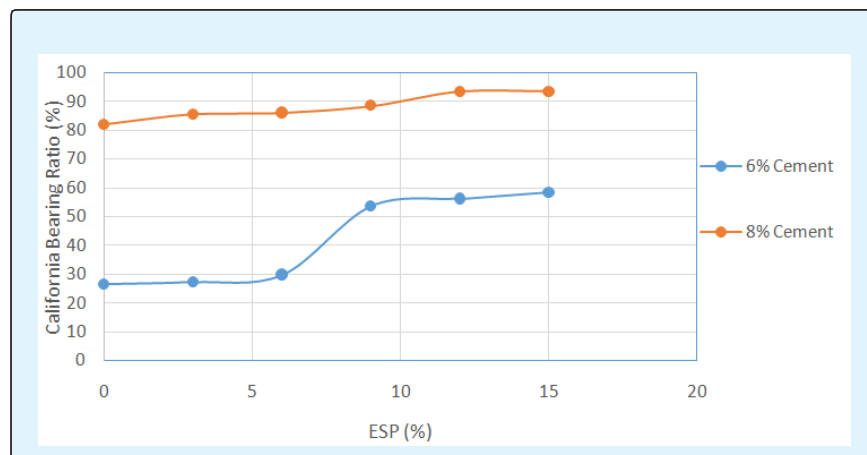

Figure 5: Variations of MDD with Increase in ESP at $6 \%$ and $8 \%$ Cement Stabilization.
Figure 5 shows the variations in California Bearing Ratio which is the strength property, with increase in eggshell ash content. The California Bearing Ratio (CBR) increased from $26.45 \%$ to $58.24 \%$ and $82 \%$ to $93.4 \%$ at $6 \%$ and $8 \%$ cement content respectively with the addition of eggshell ash from $0 \%$ to $15 \%$. This is as a result of the progressive increase in the amount of calcium oxide as due to the gradual increase in the amount of eggshell ash added to the mixtures. The increment shows that the soil sample was effectively stabilized, which in turn improved the engineering properties of the soil by making them good non-plastic sub-base material.

\section{Conclusion}

The research work has exposed the relevance of egg shell which is disposed as waste, in engineering and for stabilization purpose. The results from various laboratory tests has shown that the utilization of egg shell ash as replacement of cement or as a soil stabilizing material will improve the soil properties, thereby making the soil suitable for construction purposes. Thus, relevant authorities should collaborate in the management and disposal of this solid waste to save the environmental from pollution and encourage more researches in the field of geotechnical engineering.

\section{References}

1. Onyelowe KC, Maduabuchi MN (2017) Waste Management and Application of Waste Micro-Sized Palm Kernel Shell Ash (MSPKSA) in the Stabilization of Engineering Soil. International Journal of Waste Resources 7(2): 1-3.

2. Onyelowe KC, Ekwe NP, Okafor FO, Onuoha IC, Maduabuchi MN, et al. (2017) Investigation of the Stabilization Potentials of Nanosized-Waste Tyre Ash (NWTA) as Admixture with Lateritic Soil in Nigeria. Umudike Journal of Engineering and Technology (Ujet) 3(1): 26-35.

3. Das BM (2000) Fundamental of Geotechnical Engineering. $4^{\text {th }}($ Edn.), Thomson Learning, USA.

4. Olarewaju AJ, Balogun MO, Akinlolu SO (2011) Suitability of Egg Shell Stabilized Lateritic Soil as Subgrade Material for Road Construction. EJGE 16: 899-908.
Maduabuchi MN and Obikara FO.Effect of Egg Shell Powder (ESP) on the Strength Properties of Cement-Stabilization on Olokoro Lateritic Soil. J Waste Manage Xenobio 2018, 1(1): 000103.
Copyright $@$ Maduabuchi MN and Obikara FO. 
5. Alhassan M, Mustapha M (2007) Effect of Rice Husk Ash (RHA) on Cement Stabilized Laterite. Leonardo Electronic Journal of Practices Technologies 2: 47-58.

6. Momoh OM, Nwosu CC, Adeyinka IA (2008) Egg Production of Two Nigerian Local Chicken Ecotypes under Improved Management. Asset Series 8(2): 151158.

7. Fajobi AB, Amu O0, Oke BO (2005) Effect of Eggshell Powder on the Stabilizing Potential of Lime on an Expansive Clay Soil. Research Journal of Agriculture Biological Sciences 1(1): 80-84.

8. Kadyali LR (2006) Principles and Practices of Highway Engineering (Including Expressways and Airport Engineering). Khanna Publishers pp: 547.

9. Amu 00, Salami BA (2010) Effects of Common Salt on Some Engineering Properties of Egg Shell Stabilized
Lateritic Soil. ARPN Journal of Engineering Applied Sciences 5(9): 1-10.

10. Amu 00, Babjide SS (2011) Effects of Bamboo Leaf Ash on Lime Stabilized Lateritic Soil for Highway Construction. Research Journal of Applied Sciences Engineering Technology 3(4): 278-283.

11. BS 12 (1991) Specifications of Portland Cement. British Standards Institute, London.

12. Nigeria General Specification (1997) General Specifications (Roads and Bridges). Vol II, Federal Ministry Works and Housing, Abuja, Nigeria.

13. BS 1924 (1990) Methods of Test for Stabilized Materials for Civil Engineering Purposes. British Standards Institute, London. 